\title{
Alkaline Phosphatase Distribution in the Inferior Vagal Ganglion of the Cat Following Vagotomy***
}

\section{A Chronological Study}

\author{
Roy A. Glover*** \\ Department of Anatomy, Medical School, The Ohio State University, Columbus, Ohio 43210, \\ USA
}

Summary. The object of this study was to demonstrate sites of alkaline phosphatase activity within the cellular elements of the inferior vagal (nodosal) ganglion of the cat and chronologically observe and describe alterations in enzyme activity following vagotomy.

In control tissues alkaline phosphatase activity was localized to the wall of perineuronal blood vessels and the satellite cell cytoplasm which envelops the neuronal perikarya. In the experimental tissues alkaline phosphatase activity was increased in the above locations during the first 20 days following vagotomy then gradually declined to approximate control levels by 60 days post-operatively.

The functional significance of changes in alkaline phosphatase activity occurring within an altered metabolic environment induced by vagotomy is discussed.

\section{Introduction}

The distribution of alkaline phosphatase in the nervous system has been studied by numerous investigators. One need only consult Friede's (1966) text on the chemical anatomy of the brain for specific references. However, in spite of the available literature, very little is known about the biological significance of this enzyme. Species variation in overall levels of activity in the brain show no apparent correlation with the level of evolutionary development or with physical size. Patterns of distribution in cells and levels of activity in various neuronal groupings, i.e. nuclei, differ. The result is an almost bewildering series

\footnotetext{
* Part of a dissertation submitted in partial fulfillment of the requirements for the degree Doctor of Philosophy

** Supported by Public Health Service Fellowship 1-Fl-GM-33, 597-01 from the National Institutes of Health

*** Present address: Department of Anatomy, University of Michigan Medial School. Ann Arbor, Michigan 48109, USA
} 
of "fingerprint" patterns for each species which, at this time, defy comprehensive interpretation.

There have been identified, nevertheless, certain sites within the nervous system where alkaline phosphatase activity occurs most frequently: (1) in blood vessels; (2) diffusely in the tissue particularly in the neuropil of gray matter; (3) at all outer and inner surfaces of brain tissue and in the choroid plexus and meningeal investments. Although the mode of action of this enzyme is not understood, information derived from speculations made in early histochemical studies of brain has led to its association with several functions: impulse transmission (Fox and Bernard, 1957), release of free energy and synthesis of protein (Bourne, 1958), protection of the brain from certain noxious substances (Wislocki and Dempsey, 1948) and transfer of substances from the blood stream into surrounding neural tissue (Leduc and Wislocki, 1952; Samorajski and McCloud, 1961). Data from this study strongly supports a transport function for alkaline phosphatase while the other speculations appear highly untenable.

In comparison with the number of descriptive and quantitative studies mapping alkaline phosphatase activity in the brains of different species, very few studies have been carried out describing enzymatic changes under pathological conditions. Data accumulated from studies describing the effects of experimental brain lesions (Samorajski and McCloud, 1961; Naidoo, 1963), demyelinating diseases (Landow et al., 1942; Wolfe et al., 1943; Schiffer et al., 1962; Kirsch, 1963; O'Connor and Laws, 1963), and irradiation (Cammermeyer and Haymaker, 1958), on alkaline phosphatase activity have yielded various results. Elevated and decreased enzyme levels have been observed within comparable experimental situations and, also, between two different conditions.

Still fewer studies have been reported describing alkaline phosphatase activity within nerve cells and their associated glial cells following axon transection. This study presents evidence that alkaline phosphatase activity is increased within the inferior vagal ganglion of the cat in response to the altered metabolic conditions induced by vagotomy. This increase in alkaline phosphatase activity in ganglionic blood vessels and satellite cells may have important functional implications during the regenerative cycle of neurons following nerve transection.

\section{Materials and Methods}

Forty healthy adult cats, each weighing approximately $3 \mathrm{~kg}$, were used in this study. Animals were anesthetized with sodium pentobarbital (Nembutal, Abbott, $40 \mathrm{mg} / \mathrm{kg}$ i.p.) and the right vagus nerve was exposed and sectioned at a predetermined level $4 \mathrm{~cm}$ distal to the inferior vagal

Fig. 1. Control tissue. Note the weak reaction within the wall of the perineuronal blood vessel (arrow). Arrowheads indicate sites of varying enzyme levels in the cytoplasm of satellite cells at their interface with neuronal perikarya $(P) .(\times 250)$

Fig. 2. Fifteen day experimental tissue. At low magnification compare the intense alkaline phosphatase activity in perineuronal vessels (arrows) with the nonreactive vessels within the connective tissue capsule $(C) .(\times 150)$ 

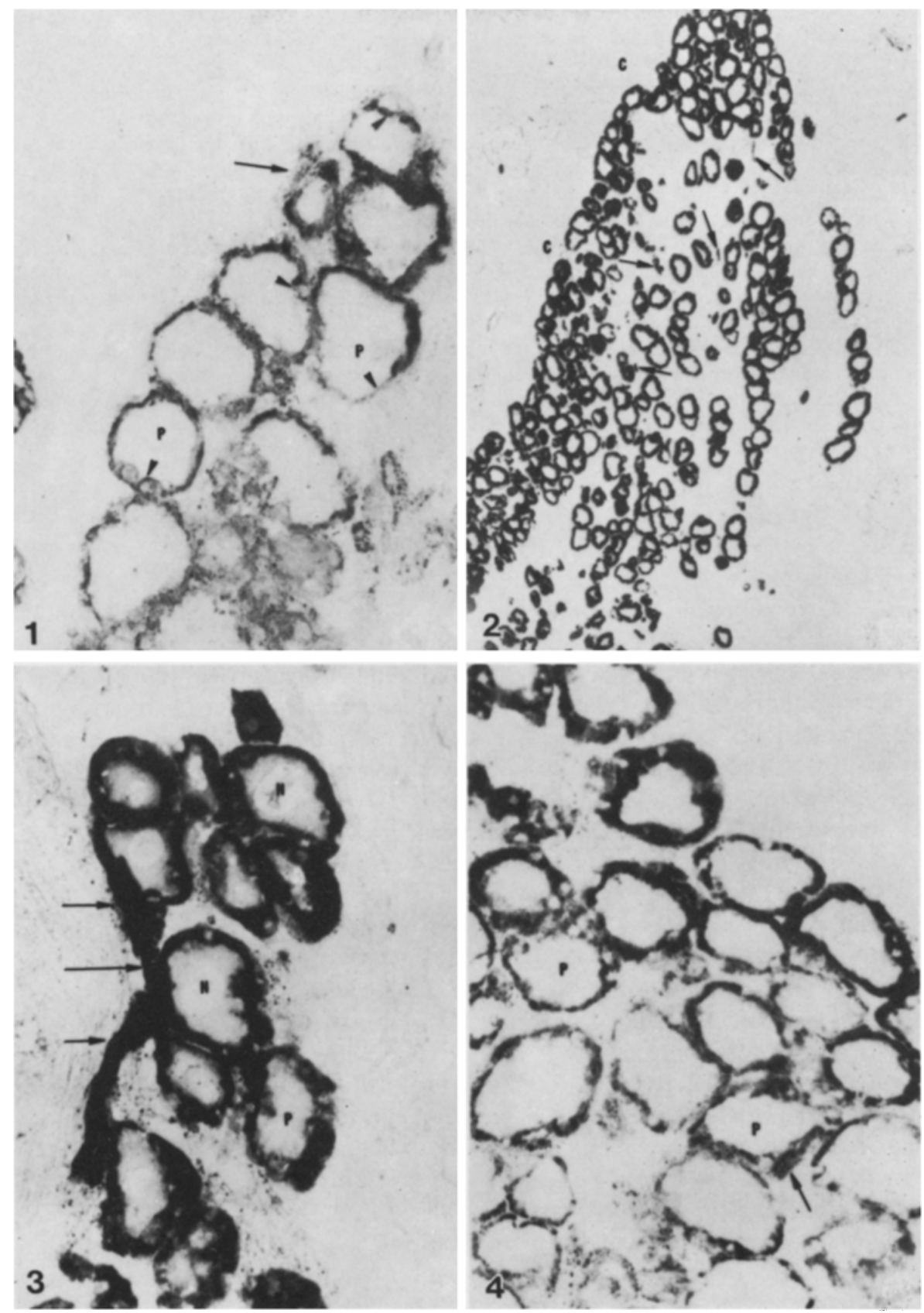

Fig. 3. Fifteen day experimental tissue. Note the level of enzyme activity in the vessel wall (arrows) and the satellite cell cytoplasm as revealed at higher magnification. The neuronal perikarya $(P)$ and nuclei $(N)$ are nonreactive. $(\times 250)$

Fig. 4. Sixty day experimental tissue. Enzyme activity is now decreased to again approach control levels in both perineuronal vessels (arrow) and the satellite cell cytoplasm investing neuronal perikarya $(P) .(\times 250)$ 
ganglion. No attempt was made to suture or approximate the severed ends. Care was taken to preserve small blood vessels which invariably accompanied the vagus nerve within the carotid sheath.

Animals were sacrified at time intervals from 1-60 days post-operatively. Experimental tissue was excised from the anesthetized animal and quick frozen immediately on crushed dry ice. Control tissue from the unoperated left side and from sham operated animals was subjected to identical procedures. Serial sections were cut at $8 \mu \mathrm{m}$ in a Harris International cryostat at $-20^{\circ} \mathrm{C}$, mounted on untreated coverslips and appropriately post-fixed in either $10 \%$ neutral-buffered formalin or cold formol-methanol for morphological and histochemical examination.

The substituted naphthol AS phosphate method of Ackerman (1962) was employed for the demonstration of alkaline phosphatase activity. This technique employing AS-MX phosphate as substrate and the diazonium salt Fast Blue RR as coupler yielded a distinct blue granular reaction product. In all cases incubations were run at $\mathrm{pH} 8.3$ for $45 \mathrm{~min}$ at room temperature. Controls for false positive enzyme activity were prepared under similar conditions with the substrate omitted from the incubating medium. All tissues were mounted in glycerine jelly.

Concomitantly, the chrome-alum-gallocyanin method of Einarson (1932) was used to verify that chromatolysis and other morphological changes indicative of altered metabolic activity could be observed for purposes of histochemical correlation.

\section{Results}

Control Tissue (Fig. 1). A variable amount of blue granular reaction product indicating sites of alkaline phosphatase activity in the inferior vagal ganglion was visualized in two major locations: (1) the wall of perineuronal blood vessels; (2) the satellite cell cytoplasm investing neuronal perikarya. Perineuronal blood vessels consistently showed a positive enzyme reaction although the reaction was weak. No visible activity was observed in vessels within the connective tissue capsule of the ganglion. Satellite cells showed varied levels of activity at points along their interface with the perikarya of large and small neurons. The perikarya themselves along with their processes were nonreactive.

Experimental Tissue (Figs. 2-4). A progressive increase in alkaline phosphatase activity was evident throughtout the first 20 days of the experimental series. Enzyme activity was ubiquitously intense in the walls of perineuronal vessels and the cytoplasm of satellite cells (Figs. 2-3). The activity in perineuronal vessels was striking when compared with the activity within capsular vessels which were still nonreactive (Fig. 2). Reaction product was also noticeably absent within the neuronal nuclei, nucleoli and cytoplasm (Fig. 3). From 25-60 days post-operatively, enzyme levels declined in all locations until, by 60 days, levels comparable with those seen in control tissue sections were apparent (Fig. 4).

The differences in enzyme activity visualized in both the control and experimental tissues were apparent at all incubation times. The optimal incubation time was $45 \mathrm{~min}$. Increasing incubation time beyond this point never revealed any more intense enzyme activity than was demonstrated at the end of the optimal time period. Reducing incubation time to $15 \mathrm{~min}$ yielded a proportionate reduction of reaction product in all tissues; the nature of the reaction product was not changed.

Control and experimental tissues, incubated in medium from which substrate had been omitted, showed a complete absence of reaction product. 


\section{Discussion}

The cytological distribution of alkaline phosphatase in peripheral ganglia has been previously described in several species at the following sites: (1) nucleoli of neurons; (2) connective tissue capsule of the ganglion; (3) peripheral neuronal cytoplasm; (4) small blood vessels; (5) cytoplasm of satellite cells (Shimizu, 1950; Tewari and Bourne, 1962; Matsuura, 1967; Shantha et al., 1967; Thakar and Tewari, 1967; Matsuura et al., 1970). In this study, enzyme activity was identified and confirmed in the latter two sites listed but not in the former three.

Alkaline phosphatase activity previously reported in the nucleoli of neurons (Shimizu, 1950; Tewari and Bourne, 1963) was not demonstrable in either control or experimental tissues. Deane (1963) has suggested that the presence or absence of nucleolar staining may depend, in part, on the histochemical method, for it appeared when the lead sulfide method was used but was absent when azo-coupling methods were employed. In this study, the use of an azo-dye technique might be responsible for the lack of nucleolar staining by eliminating the adsorption artifacts inherent in the lead sulfide method (Schiffer et al., 1962; Silva-Pinto and Coimbra, 1963).

Investigators who have described alkaline phosphatase activity in the peripheral cytoplasm of neuronal perikarya have done so based on light microscopic studies. Their micrographs, because of inadequate resolution, have failed to present convincing evidence to support this localization. Matsuura et al. (1970), using the electron microscope, was unable to demonstrate alkaline phosphatase activity within neurons of the trigeminal ganglion. In this study, localization of reaction product coincides clearly with the position of the cytoplasm of satellite cells which invest each perikaryon. Based on these observations, it is a safer interpretation to confine enzyme activity to the satellite cell cytoplasm.

Excluding pulmonary capillaries and certain sinusoids (Landers, et a1., 1962), alkaline phosphatase appears to be ubiquitously associated with the vascular system. While histochemical methods for staining alkaline phosphatase have been proposed for the demonstration of cerebral vascularization (Scharrer, 1950), Bannister and Romanul (1963) have shown that some vessels show little or no activity; the most activity occurring in small arteries and capillary networks, decreasing gradually toward the venous end. Furthermore, other studies noted that activity was distributed more widely in the vascular tree of some regions of the brain than others and that the level of activity was always species related (Sinden and Scharrer, 1949; Shimizu, 1950).

Alkaline phosphatase activity was localized in the walls of perineuronal blood vessels in both control and experimental tissues. Enzyme activity in vessels of the control series was rather weak but increased markedly during the first 20 days following vagotomy and eventually returned to approach control levels by 60 days post-operatively. No activity was visible within the vessels of the connective tissue capsule. These observations agree with several investigators who have described increased alkaline phosphatase activity in the vascular tissue of the nervous system under experimental and pathological conditions (Friede, 1961 ; Samoraski and McCloud, 1961; Naidoo, 1963) and differ from Cammer- 
meyer and Haymaker (1958) who reported decreased activity following cobalt ${ }^{60}$ (Gamma) irradiation.

Descriptive studies at both the light (Tewari and Bourne, 1964) and electron microscopic level (Matsuura, 1968; Matsuura et al., 1970) have reported alkaline phosphatase activity within satellite cells. Significant to this study is the observation of Matsuura et al., (1970) who noted an irregular deposition of reaction production at the neuron-satellite cell interface. Increased activity was particularly localized to "labyrinthine structures", areas where the cytoplasmic processes of neurons and satellite cells form extensive interdigitations. Our control tissues showed a similar irregular deposition of reaction product at the neuron-satellite cell interface. This enzymatic profile, not previously described in light microscopic studies, correlates with Matsuura's ultrastructural observations. Areas of increased enzyme activity could reasonably indicate sites of complex interrelationship of adjacent cell surfaces.

The increased alkaline phosphatase activity in satellite cells during the first 20 days following vagotomy and its subsequent decline to control levels are chronological observations which, to the author's knowledge, have not been reported elsewhere.

Nathaniel and Nathaniel (1973) have confirmed that neurons in sensory ganglia are separated from the wall of surrounding blood vessels by the attenuated cytoplasm of satellite cells. Inevitably, transport between the neuron and blood vessel must involve the satellite cell. Alkaline phosphatase activity demonstrated in both the vascular wall and the satellite cell cytoplasm might, therefore, play a role in molecular transport. If, as Pearse (1958) has stated, the quantity transported is proportionate to the width of the enzyme positive area, then enzyme fluctuations following vagotomy, when metabolic requirements of the neurons are increased and elevated synthetic activity is occurring, are logical.

The neuronal-satellite cell (glial) relationship has been described as symbiotic in character (Friede, 1965). Indeed, the hypothesis has been made that the metabolic activities of the satellite cell are related to nerve cell metabolism, and that they undergo changes as a consequence of changes in the metabolic requirements of neurons (Hydén and Pigon, 1960; Pevzner, 1971). The data reported in this study strongly reinforces this hypothesis.

Acknowledgements. The author wishes to thank Dr. James L. Hall for his advice and encouragement during the course of this study. The suggestions and critical comments of Dr. Raymond H. Kahn were also greatly appreciated.

\section{References}

Ackerman, G.A.: Substituted naphthol AS phosphate derivatives for the demonstration of leucocyte alkaline phosphatase activity. Lab. Invest. 11, 563-567 (1962)

Bannister, R.G., Romanul, F.C.A.: The localization of alkaline phosphatase activity in cerebral blood vessels. J. Neurol. Neurosurg. Psychiat. 26, 333-341 (1963)

Bourne, G.H.: Histochemical demonstration of phosphatase in the central nervous system of the rat. Exp. Cell Res., Suppl. 5, 107-117 (1958)

Cammermeyer, J., Haymaker, W.: Response of alkaline glycerophosphatase in the Macaque brain to cobalt ${ }^{60}$ (Gamma) irradiation. J. Neuropath. exp. Neurol. 17, 58-78 (1958) 
Deane, H.W.: Nuclear location of phosphatase activity: Fact or artifact? J. Histochem. Cytochem. $11,443-445$ (1963)

deSibrik, I., O'Doherty, D.S.: Phosphatases and phospholipases in the central nervous system. Arch. Neurol. (Chic.) 2, 537-546 (1960)

Einarson, L.: A method for progressive selective staining of Nissl and nuclear substance in nerve cells. Amer. J. Path. 8, 295-308 (1932)

Fox, C.A., Bernard, J.W.: A quantitative study of the Purkinje cell dendritic branchlets and their relationship to afferent fibers. J. Anat. (Lond.) 91, 299-313 (1957)

Friede, R.L.: Enzyme histochemical studies in multiple sclerosis. Arch. Neurol. (Chic.) 5, 433 (1961)

Friede, R. L.: Enzyme histochemistry of neuroglia. In: Biology of neuroglia (ed. E.D.P., De Robertis and R. Carrea), Vol. 15, pp. 35-47. Amsterdam-London-New York: Elsevier 1965

Friede, R.L.: Topographic brain chemistry. New York and London: Academic Press 1966

Hydén, H., Pigon, A. : A cytophysiological study of the functional relationship between oligodendroglial cells of Deiters' nucleus. J. Neurochem. 6, 57-72 (1960)

Kirsch, W.M.: Histochemical and quantitative analysis of alkaline phosphatase during the course of experimental intracranial neoplasia. Neurology (Minneap.) 13, 123-134 (1963)

Landers, J.W., Chason, J.L., Gonzalez, J.E., Palutke, W.: Morphology and enzymatic activity of rat cerebral capillaries. Lab. Invest. 11, 1253-1259 (1962)

Landow, H., Kabat, E., Newman, W.: Distribution of alkaline phosphatase in normal and neoplastic tissues of the nervous system. Arch. Neurol. (Chic.) 48, 518-530 (1942)

Leduc, E.H., Wislocki, G.B.: The histochemical localization of acid and alkaline phosphatases, nonspecific esterase and succinic dehydrogenase in the structures comprising the hematoencephalic barrier of the rat. J. comp. Neurol. 97, 241-279 (1952)

Matsuura, H.: Histochemical observation of bovine spinal ganglia. Histochemie 11, 152-160 (1967)

Matsuura, H.: Electronmicroscopical and enzyme histochemical studies on the trigeminal ganglion (semilunar ganglion) of the rat. [In Japanese.] J. Osaka Univ. Dent. Soc. 13, 58-66 (1968)

Matsuura, H., Hirose, I., Fujita, K. : Electron microscopic localization of alkaline phosphatase in the trigeminal ganglion of the rat. Histochemie 23, 91-97 (1970)

Naidoo, D.: Alkaline phosphatase at the site of cerebral injury. Acta histochem. (Jena) 15, 182-185 (1963)

Nathaniel, E.J.H., Nathaniel, D.R.: Electron microscopic studies of spinal ganglion cells following crushing of dorsal roots in adult rat. J. Ultrastruct. Res. 45, 168-182 (1973)

O'Connor, J.S., Laws, E.R.: Histochemical survey of brain tumor enzymes. Arch. Neurol. (Chic.) 9, 641-651 (1963)

Pearse, A.G.E. : Extension of the limits of cellular pathology. The role of enzyme histochemistry. J. clin. Path. 11, 520-534 (1958)

Pevzner, L.Z.: Topochemical aspects of nuclei acid and protein metabolism within the neuronneuroglia unit of the spinal cord anterior horn. J. Neurochem. 18, 895-907 (1971)

Samorajski, T., McCloud, J, : Alkaline phosphomonesterase and blood brain permeability. Lab. Invest. 10, 492-501 (1961)

Scharrer, E.: A technique for the demonstration of blood vessels in the developing central nervous system. Anat. Rec. 107, 319-327 (1950)

Schiffer, D., Vesco, C. Piazza, L.: Contribution to the histochemical demonstration and distribution of phosphatases and nonspecific esterase in human nervous tissue. Psych. Neurol. (Basel) 144, 34-37 (1962)

Shantha, T.R., Manocha, S.L., Bourne, G.H.: Enzyme histochemistry of the mesenteric and dorsal root ganglion cells of cat and squirrel monkey. Histochemie 10, 234-245 (1967)

Shimizu, N.: Histochemical studies on the phosphatase of the nervous system. J. comp. Neurol. 93, 201-217 (1950)

Silva-Pinto, M., Coimbra, A.: Comparative studies of the central nervous system phosphatases employing the Gomori and azo-dye methods. Acta anat. (Basel) 52, 157-173 (1963)

Sinden, J., Scharrer, E.: Distribution of certain enzymes in the brain of the pigeon. Proc. Soc. exp. Biol. (N.Y.) 72, 60-62 (1949)

Tewari, H.B., Bourne, G.H.: Histochemical evidence of metabolic cycles in spinal ganglion cells of rat. J. Histochem. Cytochem. 10, 42-64 (1962) 
Tewari, H.B., Bourne, G.H. : Histochemical studies on the discribution of alkaline and acid phosphatases and 5-nucleotidase in the cerebellum of rat. J. Anat. (Lond.) 97, 65-72 (1963)

Tewari, H.B., Bourne, G.H. : Histochemical studies on the distribution of alkaline and acid phosphatases and 5-nucleotidase in the trigeminal ganglion cells of rat. Acta histochem. (Jena) 17, 197-207 (1964)

Thakar, D.S., Tewari, H.B.: Histochemical studies on the distribution of alkaline and acid phosphatases amongst the neurons of the cerebellum, spinal and trigeminal ganglia of bat. Acta histochem. (Jena) 28, 359-367 (1967)

Wislocki, G.B., Dempsey, E.W.: The chemical cytology of the choroid plexus and blood brain barrier of the rhesus monkey (Macaca mulatta). J. comp. Neurol. 88, 319-339 (1948)

Wolfe, A., Kabat, E., Newman, W.: Histochemical studies on tissue enzymes. III. A study of the distribution of acid phosphatases with special reference to the nervous system. Amer. J. Path. 19, 423-440 (1943)

Received April 21, 1976 